International Journal of Rotating Machinery

1998, Vol. 4, No. 1, pp. 17-24

Reprints available directly from the publisher

Photocopying permitted by license only
1998 OPA (Overseas Publishers Association)

Amsterdam B.V. Published under license under the Gordon and Breach Science Publishers imprint Printed in India.

\title{
Hysteresis on Wells Turbine Characteristics in Reciprocating Flow
}

\author{
T. SETOGUCHI *, M. TAKAO and K. KANEKO \\ Department of Mechanical Engineering, Saga University, 1 Honjo-Machi, Saga-shi, Saga 840, Japan
}

(Received 13 May 1997; In final form 25 May 1997)

\begin{abstract}
The Wells turbine for a wave power generator has hysteretic characteristics in a reciprocating flow, which results in the inaccurate prediction of performance in a quasisteady analysis. In order to clarify the hysteretic characteristics, an experimental investigation has been made by use of a newly devised turbine equipment in which a sinusoidal flow condition is simulated. The results have shown that hysteresis becomes more pronounced as solidity and blade thickness become larger, but it is insensitive to the Reynolds number and blade surface roughness. By means of pressure measurements on the blade surface, it is found that the hysteresis occurs due to different behavior of wakes between an accelerating flow and a decelerating flow.
\end{abstract}

Keywords: Wells turbine, Natural energy, Wave power generator, Fluid machinery, Hysteresis, Unsteady flow

\section{INTRODUCTION}

The Wells turbine is a self-rectifying axial flow turbine suitable for energy conversion from oscillating air flow (Fig. 1). In early investigations, the model turbine testings of various rotor geometries were carried out under steady unidirectional flow conditions in order to obtain the basic characteristics of the Wells turbine (Setoguchi et al., 1986). As a result, it seemed to be possible to predict the unsteady characteristics of Wells turbine by computer simulation on the basis of the steady characteristics. However, it results in inaccurate prediction of the performance in a quasi-steady analysis, as the Wells turbine has hysteretic characteristics in an unsteady flow. The phenomenon like this at low Reynolds number and low frequency is also of considerable interest in recent year in wind energy devices and hydrofoil ship propulsion (McCroskery and Pucci, 1982; Mueller, 1985).

In this paper, in order to clarify the hysteretic characteristics, an experimental investigation has been made by use of newly devised equipment in which a sinusoidal flow condition is simulated.

*Corresponding author. Tel.: +81-952-28-8605. Fax: +81-952-28-8589. 


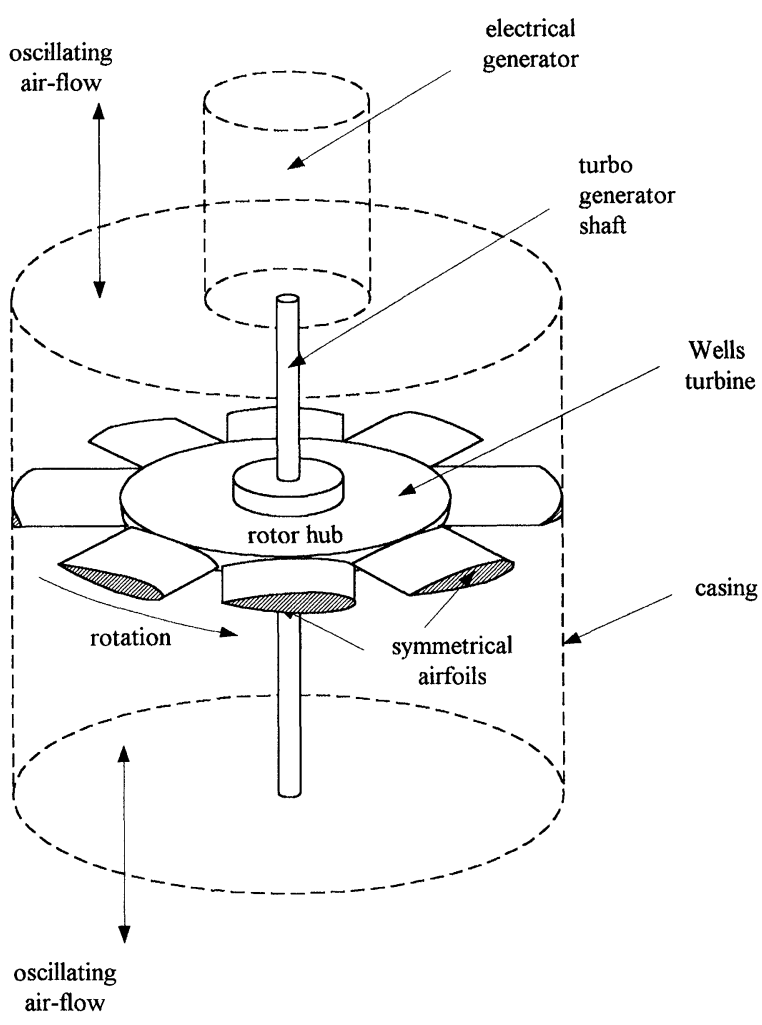

FIGURE 1 Wells turbine.

\section{EXPERIMENTAL APPARATUS AND METHODS}

The experimental apparatus used in this study is shown in Fig. 2. The test rig consists of a $1.4 \mathrm{~m}$ dia. cylinder with a piston disk, a rectangular settling chamber, and a $0.3 \mathrm{~m}$ dia. test section with a bellmouth entry and a diffuser exit. The turbine rotor with hub-to-tip ratio of 0.7 is placed at the center of the test section which is coupled to a reversible servomotor-generator through a torque transducer.

In the present study, a sinusoidal air flow was produced in order to examine the hysteretic characteristics of the Wells turbine. During the test, the turbine output torque, the air flow rate, the total pressure drop across the rotor were measured by keeping the turbine speed constant, and these data were taken into a micro-computer memory through transducer and an A/D converter to

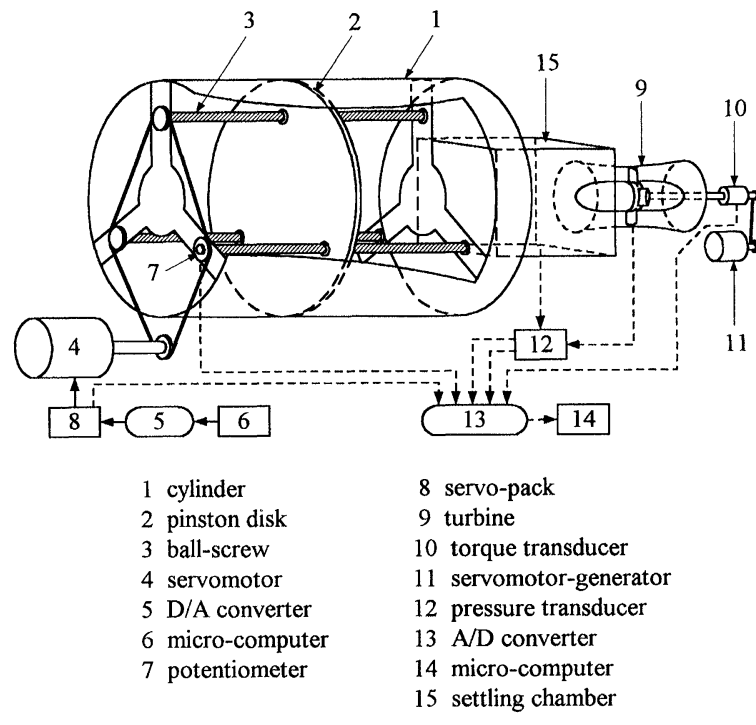

FIGURE 2 Outline of test equipment.

process the data afterward. The uncertainties of torque and pressure measurements are about $3 \%$, respectively.

Eleven kinds of rotors with various blade thickness chord ratios, aspect ratios and tip clearance were used in this work. They are tabulated in Table I, where $l$ and $z$ are chord length and number of blades, respectively. In the following discussion the individual rotor will be represented by the symbol given in the right column of the table.

The pressure distributions along the blade surface were measured at mid-span through a slip ring unit shown in Fig. 3 to clarify the cause of the hysteresis. The measured pressure is corrected taking account of the centrifugal effect due to rotor rotation.

\section{EXPERIMENTAL RESULTS AND DISCUSSIONS}

\section{Dominating Factors for the Hysteresis}

The Wells turbine rotor indicates hysteresis on the characteristics in an oscillating flow. Figure 4 shows typical hysteretic characteristics of the total pressure coefficient $\left(C_{A}\right)$ and torque coefficient 
TABLE I Specifications of turbine rotor

\begin{tabular}{lclllll}
\hline Airfoil section & $1 \mathrm{~mm}$ & $A R$ & $\sigma_{t}$ & $T C / l$ & $z$ & Symbol \\
\hline NACA0015 & 108 & 0.42 & 0.57 & 0.011 & 5 & N15-5' \\
& 90 & 0.5 & 0.48 & 0.011 & 5 & N15-5 \\
& 90 & 0.5 & 0.57 & 0.011 & 6 & N15-6 \\
& 90 & 0.5 & 0.67 & 0.011 & 7 & N15-7 \\
NACA0018 & 60 & 0.75 & 0.57 & 0.011 & 9 & N15-9 \\
& 90 & 0.5 & 0.57 & 0.011 & 6 & N18-6 \\
NACA0020 & 90 & 0.5 & 0.57 & 0.022 & 6 & \\
& 90 & 0.5 & 0.57 & 0.033 & 6 & N20-5 \\
& 90 & 0.5 & 0.48 & 0.011 & 5 & N20-6 \\
\hline
\end{tabular}

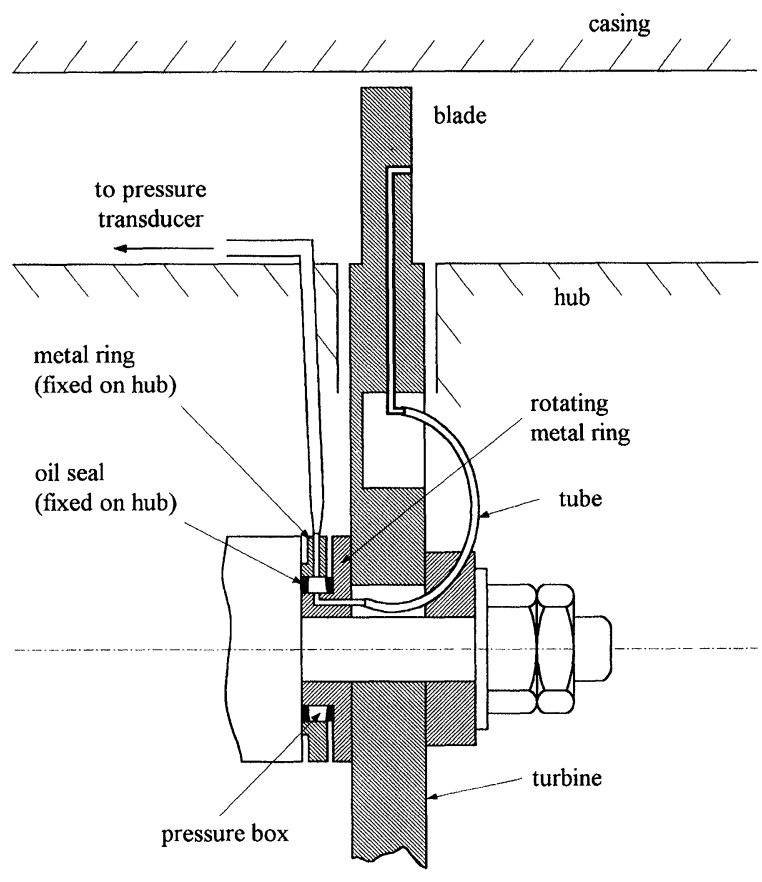

FIGURE 3 Scheme of pressure measurement on rotating blade surface.

$\left(C_{T}\right)$ against effective angle of attack $\left(\alpha_{R}\right)$ in the sinusoidal flow. These coefficients are defined as

$$
\begin{aligned}
& C_{A}=\Delta p_{0} Q /\left\{(1 / 2) \rho\left(v_{\mathrm{a}}^{2}+U_{R}^{2}\right) z b l v_{\mathrm{a}}\right\}, \\
& C_{T}=T /\left\{(1 / 2) \rho\left(v_{\mathrm{a}}^{2}+U_{R}^{2}\right) z b l r_{R}\right\}, \\
& \alpha_{R}=\tan ^{-1}\left(v_{\mathrm{a}} / U_{R}\right) .
\end{aligned}
$$
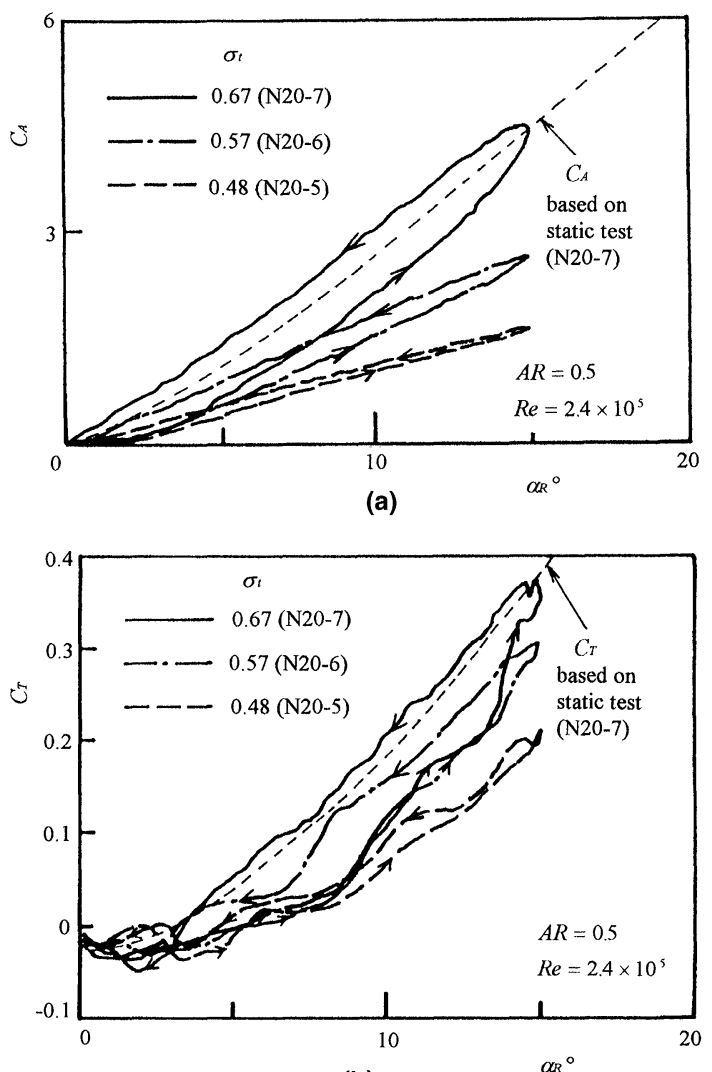

(b)

FIGURE 4 Hysteretic characteristics of Wells turbine: (a) total pressure coefficient; (b) torque coefficient.

The angle of attack varies between 0 and its maximum value in phase with the oscillating flow. In the course of the cycle, the $C_{A}$ value during 
acceleration of axial velocity (increasing $\alpha_{R}$ ) is lower than that during deceleration (decreasing $\alpha_{R}$ ), and then an anticlockwise hysteretic loop appears as shown in Fig. 4(a). The $C_{A}$ characteristics curve for steady flow condition (dashed line) lies almost in the center of the hysteresis curve. A size of the hysteretic loop increases significantly with an increase in solidity. As is evident from Fig. 4(b), a similar hysteretic loop is also observed in the torque coefficient except that $C_{T}$ curve based on static tests almost coincides with the part of hysteresis curve for decreasing process in $\alpha_{R}$.

As shown in Fig. 4, the loop on the $C_{A}$ vs. $\alpha_{R}$ curve is smoother than that on $C_{T}$ vs. $\alpha_{R}$ one because of more accurate measurement for pressure. Therefore, the hysteresis of $C_{A}$ characteristics is discussed in the following description.

Figures 5(a)-(e) show the effects of five parameters on the hysteresis, respectively. The hysteresis becomes more pronounced as blade thickness chord ratio becomes larger (Fig. 5(a)), but it is insensitive to the aspect ratio ranging from 0.42 to 0.75 (Fig. 5(b)). Figure 5(c) shows the effect of Reynolds number $R e$ on the hysteresis. In this case, the maximum angle of attack depends on $R e$ since the experiments were carried out by keeping the axial velocity constant. It seems that the hysteresis is almost independent of Re. Figure 5(d) shows the effect of blade surface roughness on it. Generally, nature of a rough surface is determined by the size, shape and distribution of roughness elements. In this work, sand grains with uniform size $k$ were distributed on the whole blade surface in order to exclude the effects of the latter two parameters. The hysteresis is not so sensitive to the relative roughness $k / l$. The effect of tip clearance $T C$ has a tendency to reduce the size of the hysteretic loop with increasing relative tip clearance $T C / l$ as shown in Fig. 5(e).

\section{Flow Mechanism of the Hysteresis}

The hysteresis of Wells turbine occurs at the angle of attack far lower than the stall angle in a steady flow. It occurs also at very low reduced frequency $\left(f l /\left(v_{a}^{2}+U_{R}^{2}\right)^{1 / 2}\right)$ which is an order magnitude of $10^{-4}$. So, it is clear that the hysteresis on Wells turbine is dissimilar to the behavior of dynamic stall (McCroskery and Pucci, 1982). Another cause to be considered at low Reynolds number and low angles of incidence may be a laminar separation bubble on the blade. Namely, the hysteresis may occur due to the appearance and disappearance of laminar separation bubble in an oscillating flow (Mueller, 1985). But, if it is the cause, the hysteretic loops on $C_{A}$ vs. $\alpha_{R}$ and $C_{T}$ vs. $\alpha_{R}$ curves shown in Fig. 4 must rotate in the opposite direction, and it must be sensitive to Reynolds number and blade surface roughness against the data in Fig. 5. Furthermore, it is unlikely to be the three-dimensional effect of flow because it is independent of aspect ratio in this experiment.

In order to clarify the mechanism of hysteresis, the measurement of pressure distribution was made along the rotating blade surface at the mean radius. The typical variations of pressure distribution for three turbine rotors are shown in Fig. 6, where the solid line and dashed lines are for the increasing and decreasing process in $\alpha_{R}$, respectively. Here the ordinate $c_{p}^{*}$ is the pressure coefficient defined by the following relation:

$$
c_{p}=\left(p-p_{1}\right) /\left\{(1 / 2) \rho\left(v_{\mathrm{a}}^{2}+U_{R}^{2}\right)\right\}
$$

As is evident from the figure, on the pressure side, there is not so noticeable difference in the pressure distributions in any case. On the suction side, however, the negative value of pressure in the decreasing process in $\alpha_{R}$ becomes higher than that in the increasing one. The difference of the pressures becomes significant with solidity. This means that the hysteretic loop on the $C_{A}$ vs. $\alpha_{R}$ curve becomes larger with an increase in solidity because the axial force coefficient (total pressure coefficient) is proportional to the area of pressure distribution on $c_{p}-x / l$ plane. These results suggest that the wake from an upstream blade interacts with a downstream blade and the effect of interaction becomes more pronounced as solidity and blade thickness become larger. The hysteresis can 


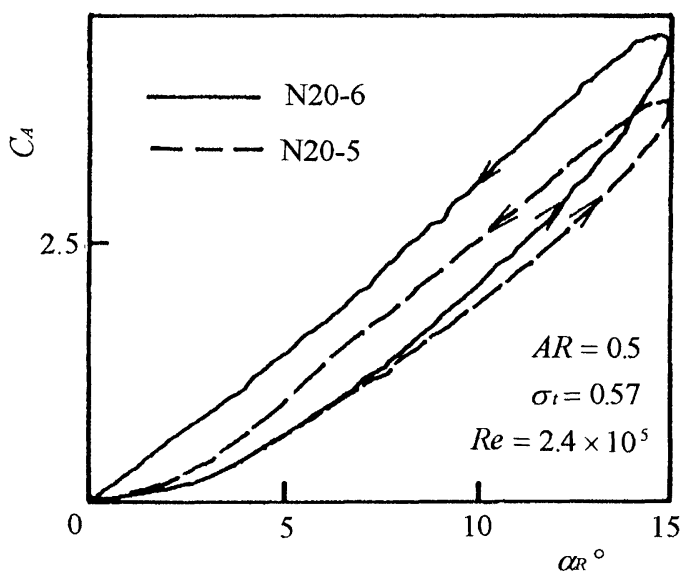

(a)

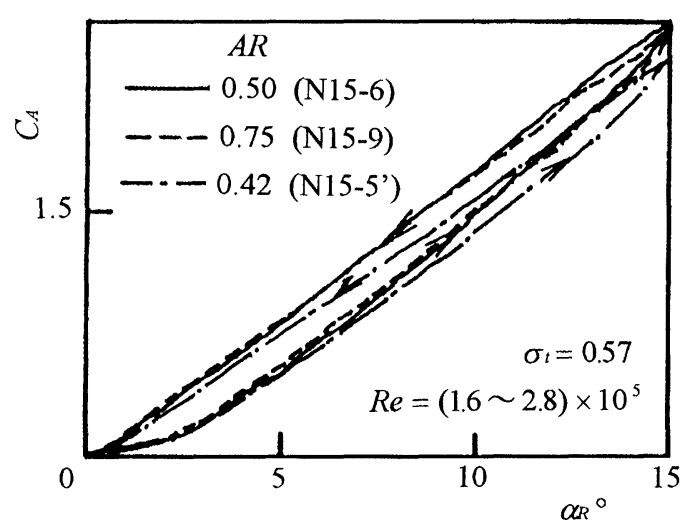

(b)

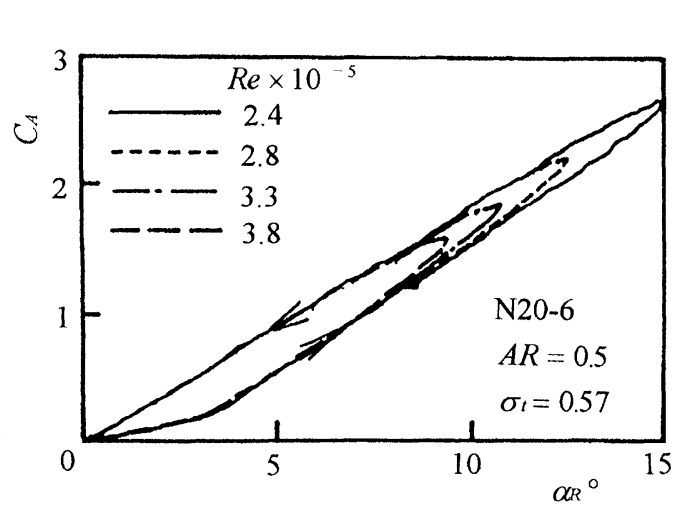

(c)

c)

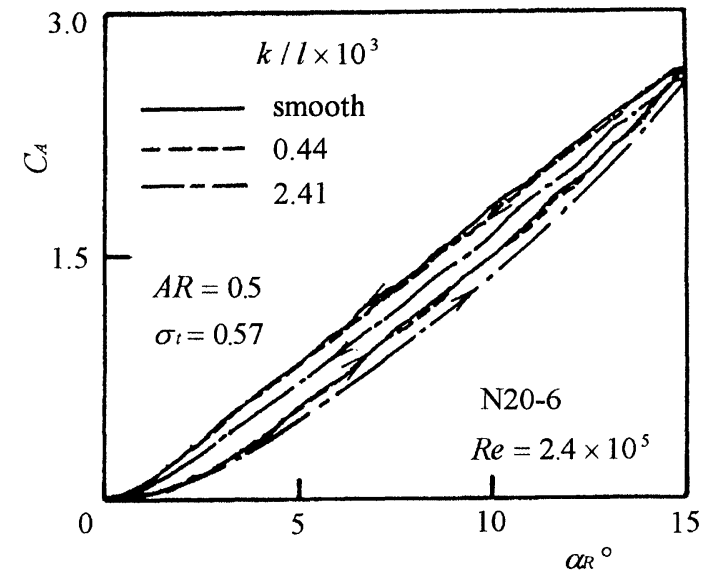

(d)

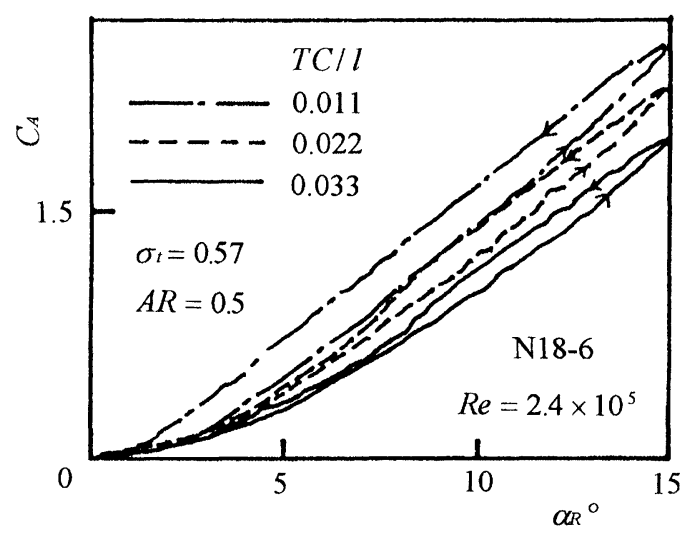

(e)

FIGURE 5 Effect of geometrical factors on hysteresis: (a) blade thickness; (b) aspect ratio; (c) Reynolds number; (d) surface roughness; (e) tip clearance. 

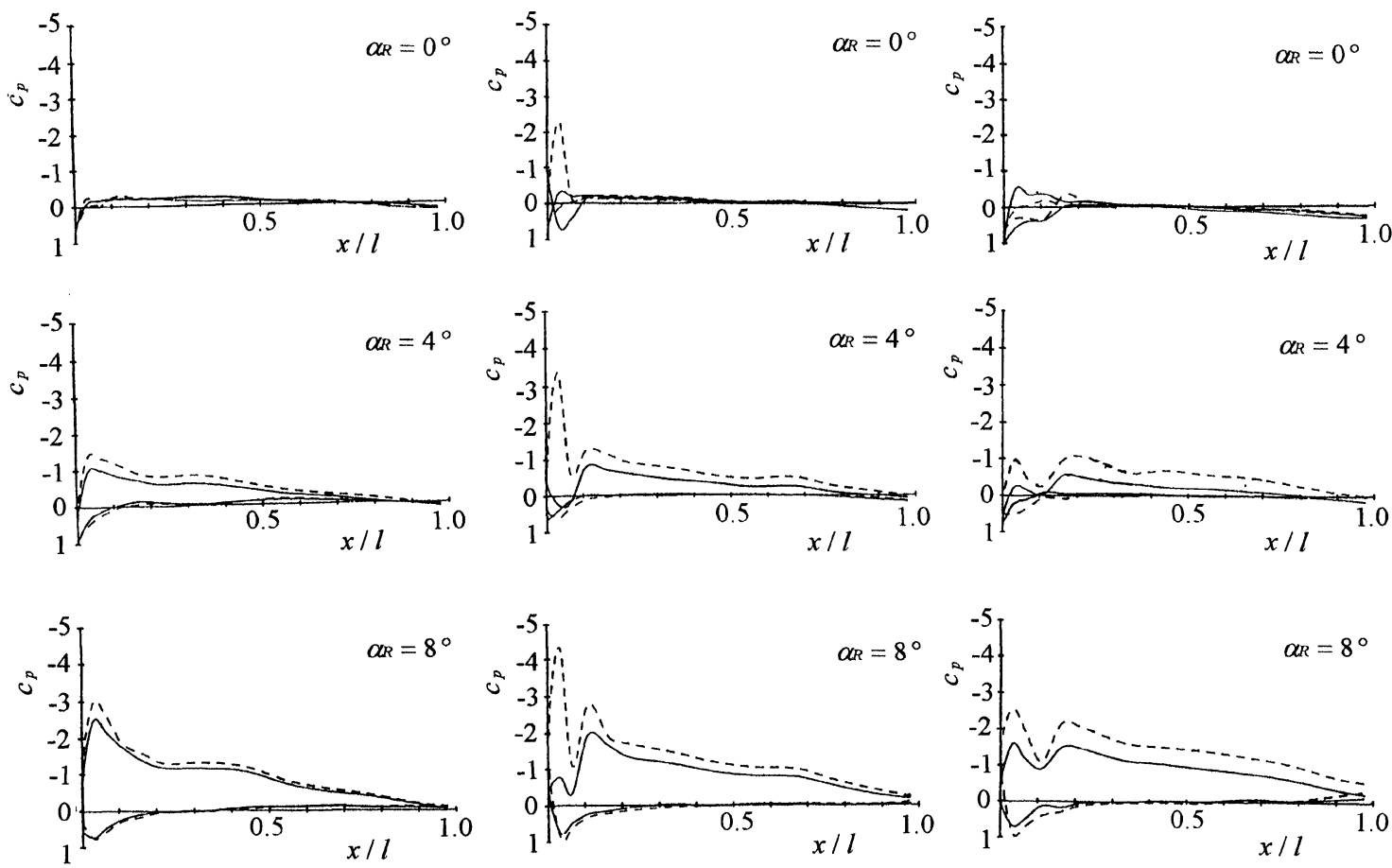

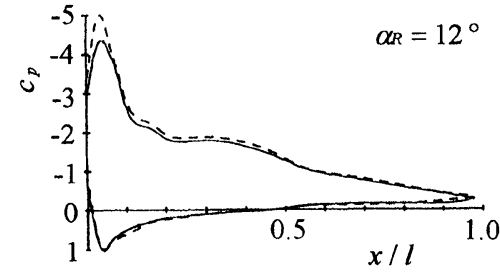

(a)

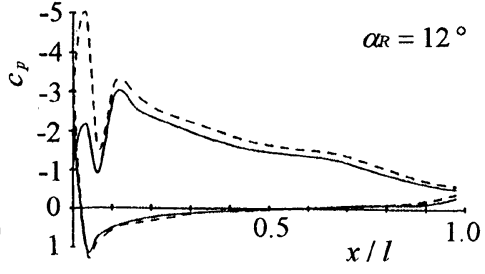

(b)

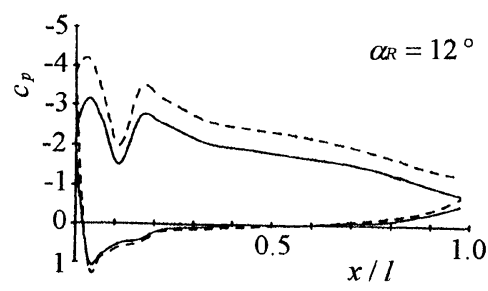

(c)

FIGURE 6 Pressure distributions along blade surface: (-) increasing process in $\alpha_{R}$; (---) decreasing process; (a) N15-5; (b) N15-6; (c) N15-7.

be appeared if the effects of wake behavior on turbine characteristics may different between an accelerating process and a decelerating process in $\alpha_{R}$.

It is necessary to make sure the relation between the hysteresis and the wake behavior on the suction side of turbine blade. In order to reduce the effect of wake from the upstream blade in the region on small $\tan ^{-1}\left(v_{\mathrm{a}} / U_{R}\right)$, the experiment was made using the special turbine rotor with setting angle of $6^{\circ}$. Figure 7 shows the $C_{A}$ vs. $\alpha_{R}$ curves for two setting angles, that is, $\gamma=0^{\circ}$ (Wells turbine) and $6^{\circ}$. A size of the hysteresis loop becomes smaller slightly in the case $\gamma=6^{\circ}$ compared with that of $\gamma=0^{\circ}$. This is due to the fact that the deflection angle in the case of $\gamma=6^{\circ}$ becomes smaller, and the wake departs from the suction side of blade. A similar phenomenon was appeared in the effect of tip clearance on the hysteresis as shown in Fig. 5(e). The interaction effect between the wake and the downstream blade weakens with an increase in tip clearance because the deflection angle becomes smaller due to decreasing circulation around blade near the tip.

So far, the flow visualization of unsteady flow field has been carried out in the two-dimensional 


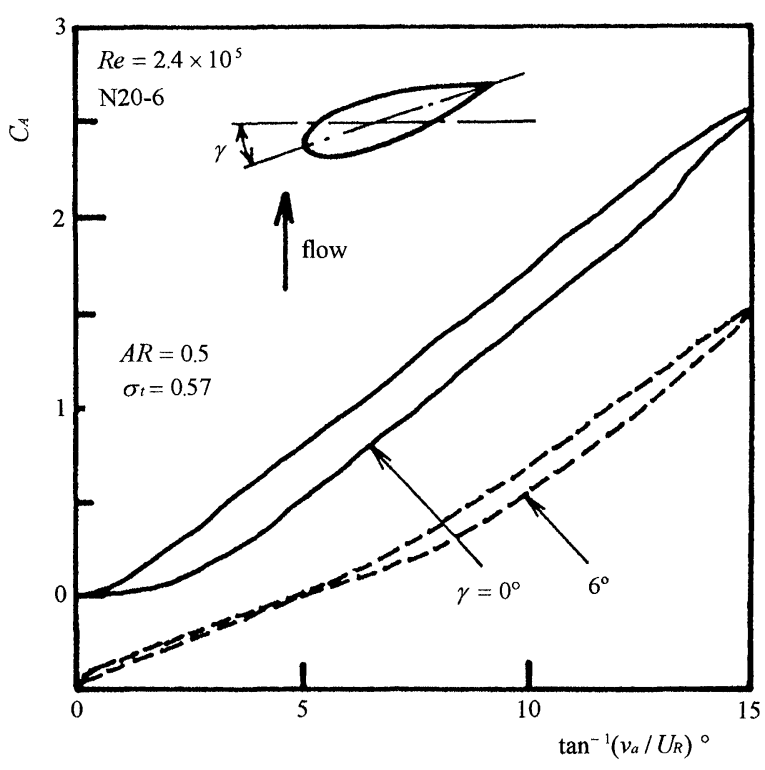

FIGURE 7 Hysteretic characteristics of turbine with setting angle.

cascade tunnel to clarify the wake behavior near the suction surface of blade (Kaneko et al., 1987). In Kaneko et al. (1987), three blades with NACA0015 profile and aspect ratio of 2.08 were set with stagger angle of $90^{\circ}$ in the tunnel, and the visualization technique adopted was paraffin mist method. According to Kaneko et al. (1987), the blade is surrounded by the wake up to a value of $\alpha=8^{\circ}$, and then the wake departs from the suction surface of blade between $\alpha=8^{\circ}$ and $10^{\circ}$ in the increasing process in $\alpha$, the wake approaches to the suction surface between $\alpha=8^{\circ}$ and $6^{\circ}$. In this way, the wake near the suction surface in the accelerating process in $\alpha$ is delayed to depart from it even in the case of small reduced frequency. This results in the reduction in $c_{p}$ on the suction surface of the hysteresis shown in Figs. 4 and 5. Furthermore, it was shown that there exists no different behavior of wake between an increasing process and a decreasing process in $\alpha$ for lower solidity. This tendency coincides with the results of Fig. 4. In addition to these result, the flow pattern of wake behavior from blade with setting angle of $6^{\circ}$, which corresponds to Fig. 7 was shown. It was found that there exists no difference of wake behavior between an increasing process and a decreasing process in $\alpha$. This is also coincident with Fig. 7.

\section{CONCLUSIONS}

The experimental investigations have been conducted to examine the hysteretic characteristics of the Wells turbine. The main conclusions are summarized as follows.

(1) The hysteretic characteristics of the Wells turbine is mainly sensitive to the solidity and blade thickness, and less sensitive to the aspect ratio, Reynolds number and blade surface roughness.

(2) The hysteresis occurs due to the different behavior of wakes between an increasing process and a decreasing process in angle of attack.

\section{NOMENCLATURE}

$A R$ aspect ratio

$b \quad$ span of blade

$C_{A}$ total pressure coefficient defined by Eq. (1)

$c_{p} \quad$ pressure coefficient defined by Eq. (4)

$C_{T} \quad$ torque coefficient defined by Eq. (2)

$f \quad$ frequency of wave motion

$\bar{f} \quad$ reduced frequency $\left(=f l / v_{\mathrm{a}}\right)$

$k \quad$ sand grain size

$l$ chord length

$p$ pressure

$Q \quad$ flow rate

$r \quad$ radius

Re Reynolds number $\left(=U_{\mathrm{t}} l / \nu\right)$

$R e_{\mathrm{s}} \quad$ Reynolds number $\left(=v_{\mathrm{a}} l / \nu\right)$

$t$ time

$T$ torque generated by rotor

$T C$ tip clearance

$U$ circumferential speed of rotor

$v_{\mathrm{a}} \quad$ axial velocity

$x$ distance measured from leading edge

$z \quad$ number of blades 
$\alpha \quad$ angle of attack

$\Delta p_{0}$ total pressure drop between settling chamber and atmosphere

$\gamma \quad$ setting angle

$\nu \quad$ kinetic viscosity

$\rho$ density of air

$\sigma \quad$ solidity

$\omega \quad$ angular velocity

\section{Subscripts}

1 inlet

$R$ mid span

$t \quad$ tip

\section{References}

Kaneko, K., Setoguchi, T. and Inoue, M., 1987. Hysteretic characteristics of wells turbine in reciprocating flow, $J$. of The Flow Visualization Society of Japan (in Japanese), 7(26), 153-156.

McCroskery, W.J. and Pucci, S.L., 1982. Viscous-inviscid interaction on oscillating airfoils in subsonic flow, AIAA J., 20(2), 167-174.

Mueller, T.J., 1985. The influence of laminar separation and transition low Reynolds number airfoil hysteresis. J. Aircraft, 22(9), 763-770.

Setoguchi, T., Kaneko, K. and Inoue, M., 1986. Determination of optimum geometry of wells turbine rotor for wave power generator (Part 1), Proc. of Current Practice and New Technology in Ocean Engineering (ASME), 2, 435-440. 


\section{ait \\ ENERGY MATERIALS}

M A N E Y publishing

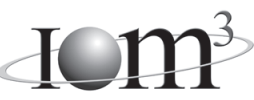

\section{Materials Science \& Engineering for Energy Systems}

Maney Publishing on behalf of the Institute of Materials, Minerals and Mining

The Institute of Materials, Minerals \& Mining

Economic and environmental factors are creating ever greater pressures for the efficient generation, transmission and use of energy. Materials developments are crucial to progress in all these areas: to innovation in design; to extending lifetime and maintenance intervals; and to successful operation in more demanding environments. Drawing together the broad community with interests in these areas, Energy Materials addresses materials needs in future energy generation, transmission, utilisation, conservation and storage. The journal covers thermal generation and gas turbines; renewable power (wind, wave, tidal, hydro, solar and geothermal); fuel cells (low and high temperature); materials issues relevant to biomass and biotechnology; nuclear power generation (fission and fusion); hydrogen generation and storage in the context of the 'hydrogen economy'; and the transmission and storage of the energy produced.

As well as publishing high-quality peer-reviewed research, Energy Materials promotes discussion of issues common to all sectors, through commissioned reviews and commentaries. The journal includes coverage of energy economics and policy, and broader social issues, since the political and legislative context influence research and investment decisions.

\section{CALL FOR PAPERS}

Contributions to the journal should be submitted online at http://ema.edmgr.com

To view the Notes for Contributors please visit: www.maney.co.uk/journals/notes/ema

Upon publication in 2006, this journal will be available via the Ingenta Connect journals service. To view free sample content online visit: www.ingentaconnect.com/content/maney

For further information please contact:

Maney Publishing UK

Tel: +44 (0)113 2497481 Fax: +44 (0)1132486983 Email: subscriptions@maney.co.uk

or

Maney Publishing North America

Tel (toll free): 8662975154 Fax: 6173546875 Email: maney@maneyusa.com

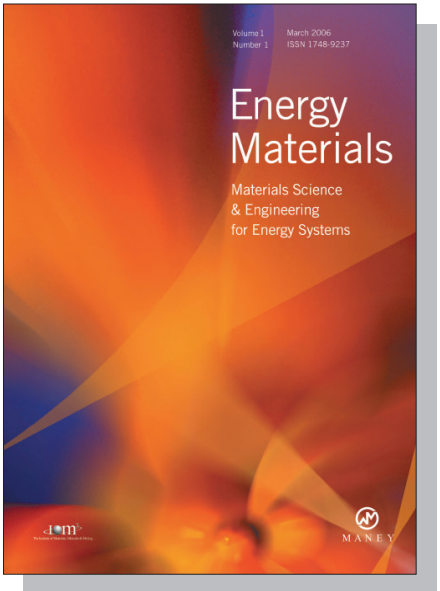

EDITORS

Dr Fujio Abe

NIMS, Japan

Dr John Hald, IPL-MPT, Technical University of Denmark, Denmark

Dr R Viswanathan, EPRI, USA

\section{SUBSCRIPTION INFORMATION}

Volume 1 (2006), 4 issues per year

Print ISSN: 1748-9237 Online ISSN: 1748-9245

Individual rate: $£ 76.00 / U S \$ 141.00$

Institutional rate: $£ 235.00 /$ US $\$ 435.00$

Online-only institutional rate: $£ 199.00 / U S \$ 367.00$

For special $\mathrm{IOM}^{3}$ member rates please email

subscriptions@maney.co.uk

\section{For further information or to subscribe online please visit www.maney.co.uk}



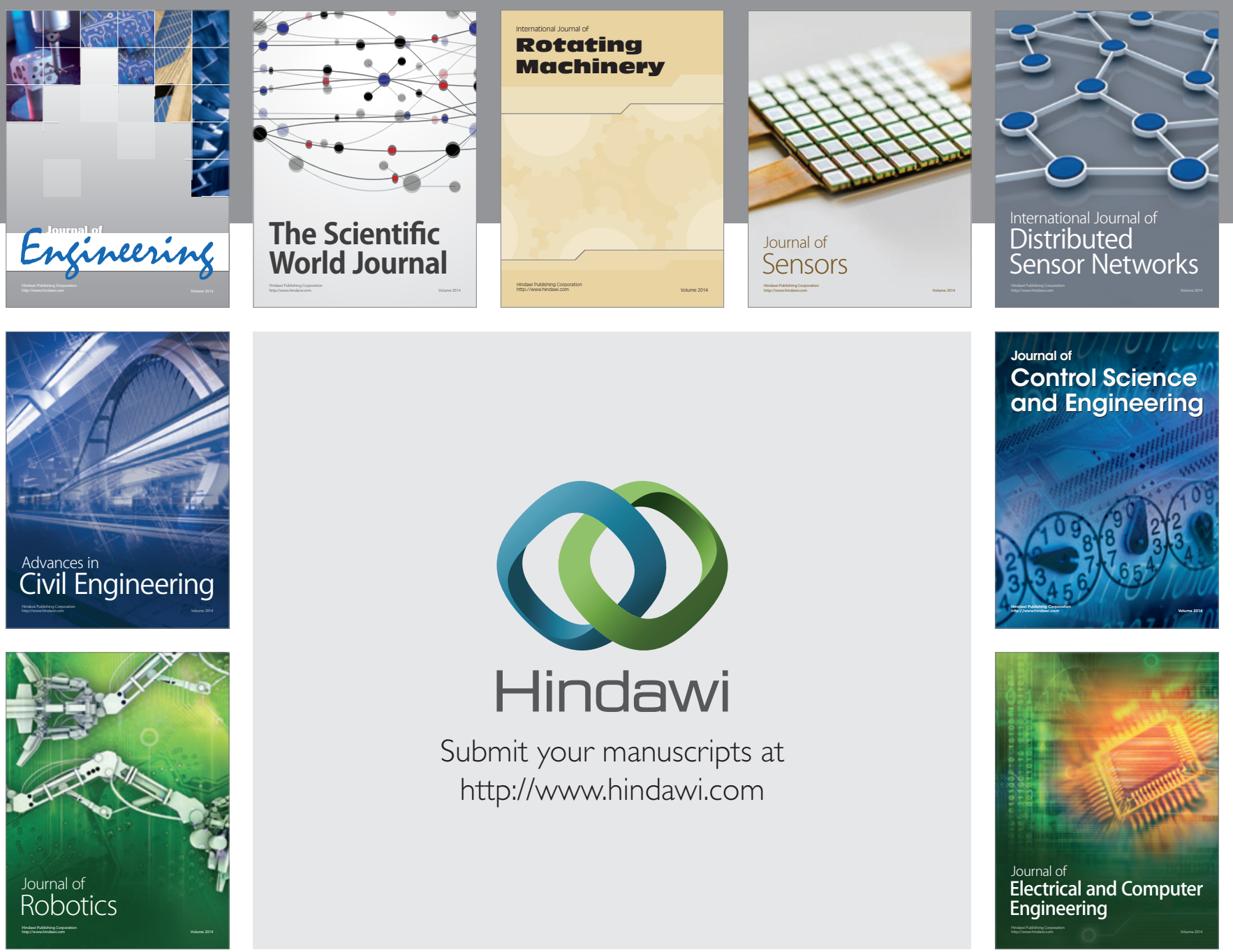

Submit your manuscripts at

http://www.hindawi.com
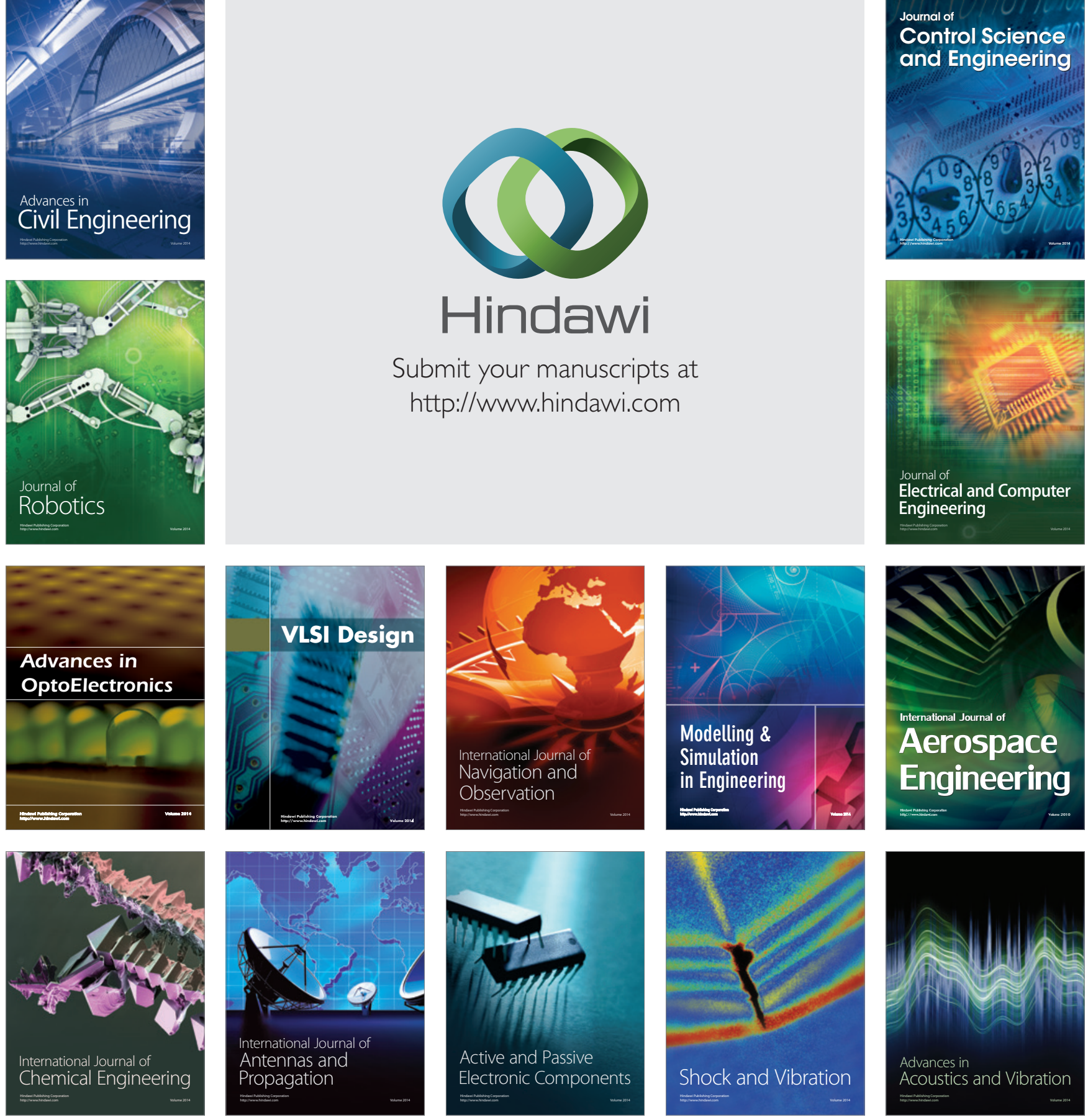